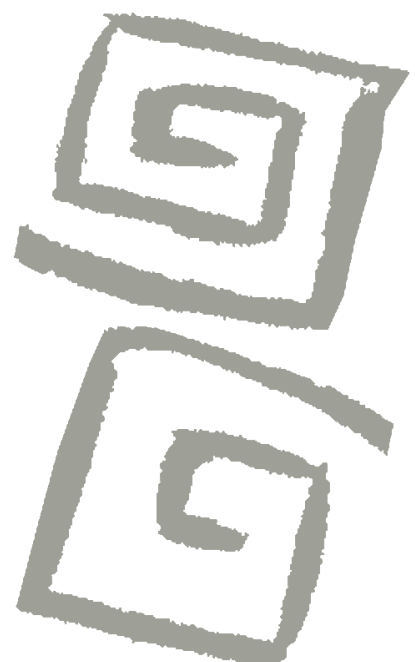

\title{
Violencia y salud pública en la prensa escrita de Guadalajara, México
}

\author{
Violence and public health in the written press of \\ Guadalajara, Mexico
}

\author{
Mejía Montoya, Cielo Cristina'; González Pérez, Guillermo Julián²; Vega \\ López, María Guadalupe ${ }^{3}$
}

'Licenciada en Ciencias y Técnicas de la Comunicación. Doctoranda en Ciencias de la Salud Pública, Centro Universitario de Ciencias de la Salud, Universidad de Guadalajara. Becaria del Consejo Nacional de Ciencia y Tecnología (CONACYT), México.

cielocriss@gmail.com

${ }^{2}$ Doctor en Ciencias de la Salud Pública. ProfesorInvestigador Titular, Centro Universitario de Ciencias de la Salud, Universidad de Guadalajara, México. ggonzal@cencar.udg.mx

${ }^{3}$ Doctora en Ciencias de la Salud Pública. ProfesoraInvestigadora Titular, Centro Universitario de Ciencias de la Salud, Universidad de Guadalajara, México. mgvega.lopez@gmail.com
RESUMEN Esta investigación busca describir cómo la prensa escrita de Guadalajara, México, representa la violencia y su vinculación con la salud pública. Para ello, se realizó un análisis de contenido mixto de las noticias de violencia publicadas en las secciones locales de los cuatro periódicos de mayor circulación de Guadalajara durante el periodo del 1 al 15 de septiembre de 2013. Se revisaron 1.465 notas locales, en las que se identificaron 399 noticias de violencia, de las cuales solo 103 mencionaban aspectos sanitarios en sus contenidos, en su mayoría referentes a los servicios médicos. En sus contenidos, la prensa no identificó la violencia como un problema de salud prioritario, sino como un asunto de inseguridad que afecta a la comunidad.

PALABRAS ClAVES Violencia; Homicidio; Noticias; Prensa; Salud Pública; México.

ABSTRACT This study seeks to describe how violence and its link to public health is represented in the written press of Guadalajara, Mexico. To this end, we carried out a mixed-content analysis of news pieces on violence published in the local sections of the four newspapers with greatest circulation in Guadalajara from the period of September 1 to 15,2013 . A total of 1,465 local news stories were reviewed, of which 399 were identified as being about violence. Of these, only 103 included healthcare aspects in their contents, generally making reference to medical services. The contents of these press articles did not identify violence as a critical public health issue, but rather as a safety issue affecting the community.

KEY WORDS Violence; Homicide; News; Press; Public Health; Mexico. 


\section{INTRODUCCIÓN}

La Organización Mundial de la Salud (OMS), en su Informe mundial sobre la violencia y la salud (1), menciona que la violencia es un problema de salud pública en casi todas las naciones del mundo. Durante el año 2013, el Instituto Nacional de Estadística y Geografía (INEGI) reportó, como cifra preliminar, que en México 22.732 personas perdieron la vida a causa de hechos violentos. Asimismo, durante el sexenio 2006-2012, la guerra contra el narcotráfico cobró 121.000 muertos $(2,3)$.

Además de ser causa de muerte, la violencia conlleva riesgos de discapacidad, trastornos psicológicos, lesiones, enfermedades, disminución en la calidad de vida y daños económicos para las víctimas y para el sector salud (4).

Los hechos violentos se publican en la prensa mediante noticias que son herramientas a través de las cuales emergen representaciones sociales sobre hechos y temas de violencia (5). En este contexto, una representación social es un sistema de valores, ideas y prácticas con doble función: la primera es orientar a las personas en el mundo social y material en tanto que, la segunda, permite la comunicación y clasificación de fenómenos y situaciones por parte de un grupo (6).

El enfoque teórico de las representaciones sociales es uno de los principales modelos de psicología social, mediante el cual se argumenta que los procesos sociales solo pueden entenderse adecuadamente si se estudian tomando en cuenta las condiciones sociales, históricas y culturales de un fenómeno (7). Estos fenómenos se desarrollan y se dan a conocer en las principales plataformas de los medios de comunicación, a través de los cuales las personas se informan del acontecer diario, lo que incluye los sucesos relacionados con la violencia (8). De acuerdo con Wagner et al. (7), la comunicación de los medios es la clave para conocer una problemática; esto es, los medios son actores sociales y/o instituciones que producen relaciones sociales y fijan lo que se habla y piensa entre quienes reciben los mensajes masivos. Otras investigaciones consideran que el personal de los medios difusores se limita a informar sobre salud tomando en cuenta solamente las frecuencias del padecimiento, dejando de lado aspectos relacionados con el estilo de vida y el medio ambiente $(9,10)$. Por su parte, Menéndez y Di Pardo (11) afirman que una constante en los medios impresos mexicanos es la publicación de temas sanitarios como catástrofes y epidemias, en lugar de manejar la información con un enfoque preventivo.

El propósito de esta investigación es describir cómo la prensa escrita de Guadalajara, México, representa la violencia y su vinculación con la salud pública.

\section{METODOLOGÍA}

Para estudiar la violencia y su relación con la salud pública en la prensa escrita de Guadalajara, utilizamos la técnica de análisis de contenido, la cual permite hacer inferencias basadas en la descripción e interpretación de datos recabados (12). Si bien originalmente se ha considerado como una técnica cuantitativa, con el tiempo ha aumentado la relevancia del enfoque cualitativo en la elaboración de interpretaciones (13), por lo que esta técnica se utiliza frecuentemente en investigaciones mixtas. Es decir, el análisis de contenido permite la existencia de un universo de prácticas sociales y cognitivas que no tienen significados únicos, sino variados (14).

Para lograr este propósito se recopilaron las notas de violencia publicadas en los diarios El Occidental, Mural, Milenio y El Informador entre el 1 y el 15 de septiembre de 2013. Dichos periódicos fueron elegidos por ser los de mayor presencia y tiraje en la zona metropolitana de Guadalajara, considerada por el Instituto Nacional de Estadística y Geografía (INEGI) como la segunda más poblada del país, con 4.434.878 de habitantes según el censo de 2010 (2).

El Informador, aunque es un periódico cuya versión impresa se distribuye solo en la ciudad de Guadalajara, es uno de los diarios más antiguos del país, pues circula desde 1917 (15). Es conocido por ser el favorito de los anunciantes (16) y, desde sus inicios, se lo identifica como un periódico tradicional y conservador que no suele tomar posiciones críticas ante el gobierno, ni ante sectores importantes a nivel nacional, ni a nivel local (17). De acuerdo con Mercado-Martínez y Ascencio-Mera (18), este periódico imprime 190.000 ejemplares diarios. 
Mural, perteneciente al Grupo Reforma, cuyo alcance es nacional, tiene el perfil editorial de una empresa liberal. Su principal objetivo es ofrecer información según las necesidades de sus lectores, sobre todo de empresarios (16). Según Trejo-Delarbre (19), aunque no puede decirse que el periódico favorezca a ciertas empresas, en ocasiones, el grupo ha subordinado la objetividad periodística por aspectos particulares. Mural publica 35.000 ejemplares por día (18).

Por su parte, Milenio, antes Ilamado Público, ha sido considerado un diario relativamente crítico, que publica 42.000 ejemplares al día $(16,18)$. Sin embargo, este periódico forma parte del grupo editorial nacional del mismo nombre que, en años recientes, ha mantenido una línea cada vez más progubernamental, en sintonía con la cadena de televisión Televisa, con la cual tiene acuerdos comerciales (20).

El Occidental, que forma parte de la Organización Editorial Mexicana, tiene un tiraje de 44.000 ejemplares diarios (21). Fregoso-Peralta (22) considera que el diario se distingue por ser defensor de las causas del Partido Revolucionario Institucional (PRI) y del neoliberalismo, con apego al gobierno.

Como criterios de inclusión para el trabajo, solo se tomaron en cuenta las notas de violencia y los accidentes publicados en las secciones locales y policiales de los periódicos. Las noticias de violencia se agruparon con base en la clasificación de la OMS, organismo que determina que existen tres tipos: la autoinfligida, la interpersonal y la colectiva (1). En los 60 ejemplares de periódicos recopilados, se contabilizaron 1.465 notas, de las cuales se eligieron 399 que cumplían con los criterios de inclusión.

\section{Técnicas de obtención de información}

Después de la recopilación, se hizo una primera lectura de cada uno de los diarios para saber cuántas noticias estaban de acuerdo con los criterios de inclusión. Con las unidades de análisis se conformó una base de datos con el fin de capturar la información referente a las categorías propuestas para el estudio: registro, jerarquía, contenidos y enfoque de salud.

En registro se incorporó la información básica de la nota, esto es, el titular, la fecha de publicación, el diario, la sección, el tema, los subtemas, la autoría, la fuente de información y la imagen. En la categoría jerarquía se estableció la cantidad de palabras que tenía la nota, la ubicación dentro de la página y si tenía fotografías. Otra de las categorías trabajadas fue la de contenidos, que permitió identificar no solo qué y cuántas notas se publicaron en los diarios sobre violencia, sino cómo se manejaron los mensajes y cuáles fueron sus actores sociales. La última categoría que se analizó en las notas fue enfoque de salud, es decir, la aparición de temáticas de salud en los textos y/o imágenes que permitieran establecer si las agresiones estaban relacionadas con la salud pública en la prensa.

\section{Análisis estadístico y temático}

Las categorías se agruparon y codificaron numéricamente usando una hoja de cálculo, mientras que los textos se escanearon para hacer una revisión cualitativa de los datos. Luego se realizó un análisis estadístico en Excel y Epi Info para medir las frecuencias y los porcentajes de los datos. Asimismo, se utilizó la prueba $\chi^{2}$ para determinar si existían diferencias estadísticamente significativas en el análisis cuantitativo del contenidos de los periódicos. Por último, para facilitar la interpretación, se identificaron valores y temas mediante un análisis temático en Atlas.ti.

El proyecto de investigación "Representaciones de la violencia en la prensa de Guadalajara, México", de donde deriva este artículo, fue aprobado en el Doctorado en Ciencias de la Salud Pública de la Universidad de Guadalajara y está registrado con la clave DCSPCCMM2013.

\section{RESULTADOS}

\section{Descripción de temas y frecuencia de la violencia en la prensa}

El $27,2 \%$ de las noticias analizadas (399 notas) estaban relacionadas, de manera directa o indirecta, con la violencia. En contraste, los contenidos exclusivos de temas especiales de salud pública que aparecieron en los diarios, durante el mismo periodo de estudio, solo sumaron el 9\% (36 notas). Aunque 


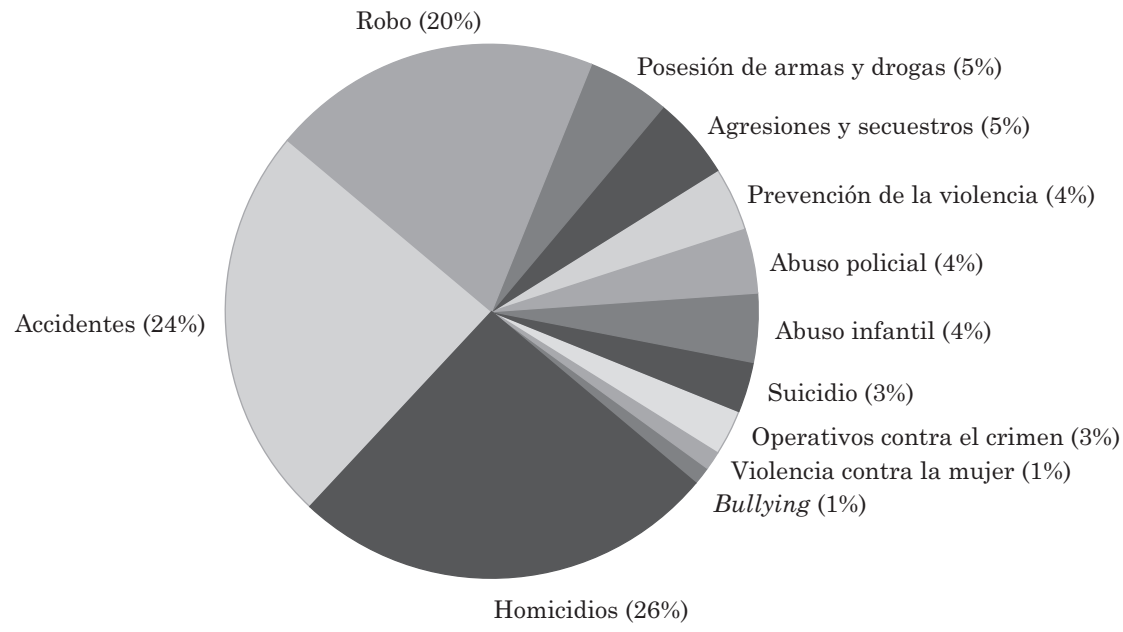

Figura 1. Distribución porcentual de las notas de violencia publicadas del 1 al 15 de septiembre de 2013 en los diarios de Guadalajara estudiados, según temas identificados.

Fuente: Elaboración propia.

se estudiaron 399 noticias de violencia, se contabilizaron 435 hechos violentos, debido a que algunas notas incluyeron varios eventos. Esta tendencia de plasmar eventos/hechos condensados fue utilizada en las redacciones de los diarios Mural, Milenio y El Informador, no así en El Occidental.

El $85 \%$ de la información sobre violencia (340 notas) fue publicada en la sección policial de cada diario; la mayor parte de estas noticias se refería tanto a violencias interpersonales (robo, homicidios, agresiones y secuestros) como a accidentes. El $15 \%$ restante (59 notas) se publicó en las secciones locales de los periódicos, en las que prevalecían los tópicos de prevención de la violencia, suicidio y violencia contra la mujer. La Figura 1 muestra la distribución porcentual de los temas identificados en el estudio.

El homicidio fue el tema de violencia sobre el que más se publicó en la prensa, ya que apareció en el $26 \%$ de las notas, mientras que los accidentes y los robos se ubicaron en el segundo y tercer lugar con el $24 \%$ y el $20 \%$, respectivamente. Estos tópicos también fueron los que se publicaron con más frecuencia en las primeras planas y portadas de los diarios, por lo que tuvieron una mayor jerarquía que el resto. Otros temas que se identificaron fueron la posesión de armas y drogas, las agresiones y secuestros, la prevención de la violencia, el abuso policial, el abuso infantil, el suicidio, los operativos contra el crimen, la violencia contra la mujer y el bullying. La presencia de estas notas fluctuó entre el $5 \%$ y el $1 \%$.

Como ya se mencionó, las notas se agruparon según la clasificación de la OMS, que incluye violencias autoinfligidas, interpersonales -intrafamiliares y comunitarias en grupos pequeños- y colectivas, y también se consideraron las noticias de accidentes. En este contexto, se encontraron 231 notas sobre violencia interpersonal, 94 sobre accidentes, 62 sobre violencia colectiva y 12 sobre violencia autoinfligida.

Los robos, agresiones y secuestros, casos de bullying y homicidios fueron agrupados como hechos de violencia interpersonal, aunque solo del subtipo comunitario. Por otra parte, el maltrato dirigido a niños, ancianos y mujeres dentro la familia integró las noticias sobre violencia intrafamiliar. Las temáticas colectivas fueron el abuso policial y los operativos contra el crimen.

A pesar de las diferencias editoriales entre periódicos, no hubo diferencias estadísticamente significativas en el análisis cuantitativo de los contenidos publicados en los diarios $(p=0,6672)$, con respecto a los tipos de violencia analizados en las noticias (Cuadro 1). No obstante, aunque no se observaron variaciones cuantitativas significativas, sí hubo divergencias cualitativas, las cuales se referirán más adelante. 
Cuadro 1. Notas de violencia publicadas del 1 al 15 de septiembre de 2013 en los diarios de Guadalajara estudiados, según tipo de violencia $(\mathrm{N}=399)$.

\begin{tabular}{|c|c|c|c|c|c|c|c|c|c|}
\hline \multirow[t]{3}{*}{ Diario } & \multicolumn{8}{|c|}{ Tipo de violencia } & \multirow[t]{3}{*}{$p$-valor } \\
\hline & \multicolumn{2}{|c|}{ Autoinfligida } & \multicolumn{2}{|c|}{ Interpersonal } & \multicolumn{2}{|c|}{ Colectiva } & \multicolumn{2}{|c|}{ Accidentes } & \\
\hline & $\mathrm{n}$ & $\%$ & $\mathbf{n}$ & $\%$ & $\mathrm{n}$ & $\%$ & $\mathbf{n}$ & $\%$ & \\
\hline El Occidental & 5 & 3,5 & 76 & 53,1 & 25 & 17,5 & 37 & 25,9 & \multirow{4}{*}{0,6672} \\
\hline Mural & 1 & 0,9 & 64 & 60,4 & 16 & 15,1 & 25 & 23,6 & \\
\hline Milenio & 5 & 5,6 & 51 & 57,3 & 13 & 14,6 & 20 & 22,5 & \\
\hline El Informador & 1 & 1,6 & 40 & 65,6 & 8 & 13,1 & 12 & 19,7 & \\
\hline
\end{tabular}

Fuente: Elaboración propia.

Nota: Valor de $\chi^{2}=6,7107$ para 9 grados de libertad.

En general, de las 399 notas, 266 (67\%) fueron redactadas por reporteros; $55(14 \%)$ por la redacción de los diarios, y 78 (19\%) fueron notas sin firma. La fuente de información que más se identificó en las noticias fue la oficial o de gobierno, que estuvo presente en el $47 \%$ de las informaciones; por el contrario, el testimonio de las víctimas de los actos violentos solo apareció en el $1 \%$ de los casos. Casi el $60 \%$ de las noticias tenía imágenes, gráficos o tablas. Las fotografías más comunes eran las que reportaban el hecho y el lugar, sobre todo en las notas referidas a accidentes, homicidios, robos, y agresiones y secuestros, en las que se mostraban imágenes de vehículos chocados, patrullas y ambulancias, heridos en camillas siendo atendidos por personal de emergencias e, incluso, muertos -casi todos varones- cubiertos con mantas y, en algunas casos, fotografías explícitas de cadáveres, aunque solo en El Occidental. En temas relacionados con casos de posesión de drogas y armas, las imágenes más frecuentes eran las de los detenidos mientras que, en tópicos como bullying, suicidio y violencia intrafamiliar, se utilizaban imágenes temáticas.

El $47 \%$ del total de notas analizadas incluían reportes de personas que perdieron la vida a causa de hechos violentos y accidentes. En números, la cantidad de personas fallecidas reportadas en las noticias durante el periodo de estudio fue de 132 : 78 asesinados (59\%), 52 muertos por accidentes (40\%) y dos víctimas de suicidio (1\%).

\section{Actores sociales de las notas de violencia en la prensa}

La mayoría de los personajes descritos en las noticias eran varones jóvenes. Estos representaban roles de agresores, pero también de agredidos:

\begin{abstract}
Un joven que antes había herido a otro durante una riña de pandillas en la Colonia Jalisco, fue encontrado con un revólver calibre.38. (Nota informativa) (23)
\end{abstract}

Asimismo, las autoridades y la mayor parte de las fuentes de información que aparecían en el reporte de las noticias también eran del sexo masculino. Es importante resaltar que las notas, en su mayoría, estaban escritas por reporteros varones. Las mujeres y los menores de edad aparecían poco en el análisis y, mayoritariamente, eran representados como víctimas:

\footnotetext{
Fuerte discusión entre padre e hija sólo pudo ser callada con el sonido de las balas, y es que el fúrico sujeto le disparó a la chica [...] (Nota informativa) (24)
}

Sin embargo, en menor escala, estos actores sociales -mujeres y adolescentes- también desempeñaron papeles de agresores: 
Todas unas fichitas resultaron ser dos menores de edad que fueron retenidos por policías de Guadalajara, y es que el par de muchachos aprovechaba las horas nocturnas para cometer innumerables fechorías [...] (Nota informativa) (25)

Ya no es extraño que una madre atente contra sus hijos, ya sea golpes, ofensas, incluso hasta la muerte; esta vez no fue la excepción, pues una mujer vecina de Tonalá decidió entrar a la casa de su hija sin que se diera cuenta para llevarse artículos de valor [...] (Nota informativa) (26)

Cuando los menores de edad o las mujeres tenían roles negativos dentro de los hechos, el reportero comúnmente incluía calificativos en la redacción de la noticia. Los agentes policiales jugaban un doble rol: en algunas notas, sobre todo en El Occidental, se los llamaba "guardianes del orden", pero en otras se los describía como corruptos. Los hombres aparecían más en notas relacionadas con homicidios, accidentes, robos, operativos contra el crimen, agresiones y secuestros, y posesión de drogas y armas, mientras que las mujeres, los niños y los ancianos solían aparecer como víctimas en noticias sobre violencia intrafamiliar, abuso infantil y violencia contra la mujer.

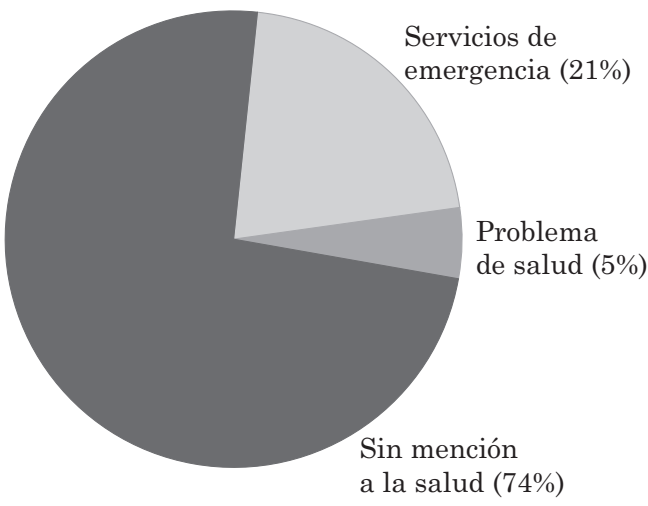

Figura 2. Distribución porcentual de los aspectos de salud mencionados en las notas de violencia publicadas del 1 al 15 de septiembre de 2013, en los diarios de Guadalajara estudiados.

Fuente: Elaboración propia.

\section{Vínculos entre la violencia y la salud pública en la prensa escrita}

Las notas sobre violencia relacionadas con la salud sumaron el 26\% de la muestra: 103 de 399 notas. En el resto de las noticias no se mencionaban temas sanitarios (Figura 2). De las 103 noticias que sí tenían un vínculo con temas sanitarios, el 82,5\% mencionaba los servicios de atención médica que requirieron las víctimas de los actos violentos y los accidentes, mientras que solo en el $17,5 \%$ de las notas se consideró algún acto violento como un problema de salud, especialmente en los casos de suicidio o bullying.

Las noticias que abordaban aspectos sanitarios solo describían la intervención de paramédicos en el hecho $y$, aunque se mencionaban los servicios médicos, éstos tenían una función secundaria, ya que el suceso principal era la agresión como fenómeno social o judicial, mientras que la aparición del personal de salud era un elemento subsecuente de la nota.

\section{Violencia y salud en los diarios}

De las notas seleccionadas del diario Milenio, $27(30,3 \%)$ mencionaban aspectos de salud y 9 describían la violencia como un problema de salud pública. Por su parte, de las 143 notas de El Occidental, 41 (28,7\%) hacían alusión a temas sanitarios, 37 mencionaban los servicios de salud y cinco mostraban la violencia como una problemática que enferma a la población. Mural y El Informador solo tuvieron dos notas cada uno en las que argumentaban que la violencia es una problemática sanitaria, aunque los servicios médicos fueron citados en 31 notas: 21 del primero y 10 del segundo.

Para revisar estas variantes, también se hizo una prueba estadística (Cuadro 2), con la que se comprobó que las diferencias entre los diarios no fueron significativas $(p=0,2958)$.

\section{Agresiones, homicidios y salud}

En las 105 notas sobre homicidios que se analizaron en el estudio, el $73 \%$ no incluyó cuestiones de salud, mientras que en el $27 \%$ sí se mencionó a los servicios médicos. No obstante, en ningún mensaje se informaba que el homicidio es 
un problema de salud pública, sobre todo para la población joven y de sexo masculino. En el análisis tampoco se encontraron notas sobre costos, atención médica, discapacidad o años de vida potencialmente perdidos provocados por una lesión intencional.

\section{Accidentes y su vínculo con la salud}

El $50 \%$ de las notas sobre lesiones no intencionadas carecía de vínculos con temas de salud. No obstante, en un $48 \%$ de las noticias sobre accidentes se hacía mención a los servicios de atención médica, mientras que solo en el $2 \%$ de las noticias se describían los accidentes como un problema de salud.

\section{Suicidio, bullying y violencia contra la mujer como problemas de salud}

Estos tópicos fueron considerados como problemas de salud pública en los diarios. De las 12 notas sobre suicidio, en diez se describía la violencia autoinfligida como un tema en el que deben coadyuvar la comunidad y el personal de salud para evitar el fenómeno. En el caso de buIlying, en las cuatro notas analizadas se reportó que el sector salud debía involucrarse más con ese conflicto, al igual que en las notas sobre violencia contra la mujer, clasificada como un asunto de salud pública.

\section{Robos y otros temas desde el ámbito sanitario}

En las notas sobre operativos contra el crimen organizado, casos de abuso policial, robos y posesión de armas y drogas, no se encontraron temas relacionados con la salud. Por ejemplo, si bien la posesión de una cantidad de drogas ilegales mayor a la permitida por la ley es considerada en México como un delito contra la salud, en ninguna de las notas al respecto se hacía énfasis en los daños que estas pueden ocasionar.

\section{Violencia, salud y atributos}

El $32 \%$ de los contenidos sobre violencia tenía calificativos; es decir, en 129 de 399 textos se expuso algún tipo de atribución. En este apartado se detectaron algunas diferencias en el
Cuadro 2. Notas de violencia publicadas del 1 al 15 de septiembre de 2013 en los diarios de Guadalajara estudiados, según mención sobre aspectos sanitarios $(\mathrm{N}=399)$.

\begin{tabular}{|c|c|c|c|c|c|}
\hline \multirow[t]{3}{*}{ Diario } & \multicolumn{4}{|c|}{$\begin{array}{c}\text { Mención sobre aspectos } \\
\text { sanitarios }\end{array}$} & \multirow[t]{3}{*}{$p$-valor } \\
\hline & \multicolumn{2}{|c|}{ Sí } & \multicolumn{2}{|c|}{ No } & \\
\hline & $\mathbf{n}$ & $\%$ & $\mathbf{n}$ & $\%$ & \\
\hline El Occidental & 41 & 28,7 & 102 & 71,3 & \multirow{4}{*}{0,2958} \\
\hline Mural & 23 & 21,7 & 83 & 78,3 & \\
\hline Milenio & 27 & 30,3 & 62 & 69,7 & \\
\hline El Informador & 12 & 11,7 & 49 & 80,3 & \\
\hline
\end{tabular}

Fuente: Elaboración propia.

Nota: Valor de $\chi^{2}=3,6996$ para 3 grados de libertad.

tratamiento de la información entre los diarios, ya que El Occidental concentró el $56 \%$ de los calificativos y opiniones del total de notas, mientras que Mural reunió el $16 \%$, Milenio el $15 \%$ y El Informador el $13 \%$. Esto quiere decir que El Occidental fue el periódico que hizo más juicios de valor e incluyó más adjetivos calificativos en sus contenidos, mientras que El Informador fue el que tuvo menor cantidad de estas características durante el período estudiado.

En el caso de las noticias en las que se identificó algún vínculo entre violencia y salud, se encontró que 39 notas sobre homicidios, agresiones y accidentes tenían calificativos como, por ejemplo, la nota "Imprudentes choferes provocan choque" (27) publicada por el diario El Occidental, en la que se incorpora un adjetivo en el titular.

\section{DISCUSIÓN}

En los mensajes de los diarios estudiados no se identifica la violencia como un problema de salud importante para la comunidad (28). Es decir, no se hace énfasis en la relación entre salud pública y hechos violentos; por tanto, en la mayoría de las notas no se transmite este fenómeno como un conflicto multifactorial que puede prevenirse y combatirse con medidas no violentas. Solo pocas informaciones, principalmente sobre suicidio, buIlying, abuso infantil y violencia contra la mujer 
tuvieron un enfoque más crítico y preventivo por parte del redactor. Mediante este tipo de coberturas, la comunicación ayuda al campo de la salud pública, pues activa a los lectores a desarrollar roles como pacientes potenciales de algún problema (29).

Por otra parte, y aunque en los homicidios y los accidentes sí se mencionaron los servicios médicos, no se hizo énfasis en los costos ni en el estado físico y/o psicológico de la víctima o los testigos. Es decir, la prensa ve a la práctica médica y al sector salud como un apoyo después de ocurrido un hecho violento, pero no los ve participando en su prevención. Por ello, los paramédicos solo se presentaron como actores secundarios en las noticias; además, casi no hubo declaraciones de especialistas en áreas sanitarias.

Menéndez y Di Pardo (11) mencionan que cuando la prensa en México difunde temas relacionados con los procesos de salud-enfermedadatención de las víctimas, por lo general, hace representaciones sociales negativas. Un ejemplo observado fue el tema del suicidio, sobre todo cuando se habla de cifras y casos consumados en niños. Cabe resaltar que, durante la recolección de notas, se celebró el Día Mundial para la Prevención del Suicidio, lo que pudo haber incrementado las notas sobre este tópico.

Ciertos autores refieren que el miedo que se transmite en las noticias favorece a estas representaciones sociales negativas, incrementando así la inseguridad de los usuarios de los medios, pues estos pueden sentirse en peligro ante la ocurrencia de un evento ligado a agresiones, es decir, la nota roja -mediante su vocabulario, jerarquía e imagencausa temor y preocupación en la audiencia $(11,30)$. En los textos analizados, los testigos expresaban temor de sufrir alguna agresión, pero este miedo no se vinculaba con enfermedades o lesiones, sino con la posibilidad de perder objetos valiosos o morir. En general, en los cuatro periódicos estudiados, las noticias tenían un tratamiento encaminado a mantener el control de la estructura social; o sea, se promovían valores e ideas de autoridades, que eran la principal fuente informativa de los textos.

No se identificaron noticias que buscaran explicar las causas del hecho delictivo, pero sí se percibió la intención de etiquetar a las personas como "buenas" o "malas". Federico et al. (28), plantean la hipótesis de que en los diarios "se utiliza una terminología diferente para hacer referencia a las muertes de policías respecto de las de los 'delincuentes', así como también en relación a diferencias de 'clase social'". En el presente estudio, a quien delinquía se lo calificaba de "malandro", mientras que el papel de las autoridades, los académicos y los especialistas en el área de la salud era más neutro. Por otra parte, los agredidos tenían roles pasivos y pocos testimonios. Ocasionalmente, las víctimas mortales eran exhibidas como objetos en las fotografías y en los textos.

La investigación permitió observar las relaciones de poder entre los actores sociales. En las noticias, a través de roles de subordinación, se victimizaba a mujeres, niños y ancianos con más ímpetu que a los varones jóvenes. Otro hallazgo que puede reportarse es la masculinización de la violencia en la prensa, ya que incluso hay más reporteros hombres realizando este tipo de coberturas periodísticas.

La esperanza de vida en México no ha crecido de forma significativa en los varones debido a los altos niveles de violencia homicida actuales (31). Incluso, cifras del INEGI reportan que en México la primera causa de muerte en hombres jóvenes -de 14 a 25 años- son los hechos violentos (2).

Sin dejar de considerar que el objetivo primordial de la prensa escrita es vender publicidad y ejemplares, se puede afirmar que la prensa cumple con otras funciones, una de las cuales es informar sobre los hechos violentos. Asimismo, por su lenguaje y agenda de temas, también cumple con la tarea de brindar entretenimiento. Una de las razones por las cuales la violencia es atractiva para el público es porque, además de despertar curiosidad, los actos de agresión en las noticias permiten que el espectador sienta empatía por las víctimas y rechazo por los agresores (32).

En esta investigación se identificó que la prensa prioriza la selección de noticias de accidentes y homicidios sobre otros temas, como la violencia contra la mujer, la prevención de la violencia y el bullying. Al analizar la agenda de los medios, Vázquez-González (33) menciona que las representaciones sociales que brindan los medios están determinadas justamente por la selección y el contexto que tienen las noticias, las cuales deben tener interés público.

En las notas, el sector salud local no dio ruedas de prensa sobre temas de violencia relacionados 
con el crimen organizado, como es el caso de los homicidios. En cambio, los accidentes sí fueron explicados desde el enfoque de las instituciones, aunque una investigación sobre el reporte de accidentes en las noticias de diarios de Guadalajara concluyó que los periódicos deben incentivar todavía más la cultura de la prevención en sus contenidos (34). Con lo anterior, podemos concluir que no hay evidencia en la prensa escrita de que el sistema de salud trabaje la violencia desde un punto de vista epidemiológico y sanitario, sino que, por el contrario, la prensa escrita construye los temas y hechos como si fueran problemas irreparables, respecto de los cuales la salud pública no puede hacer nada. Por tanto, no existe una postura oficial del fenómeno violencia por parte del sector, ni consejos multidisciplinarios al respecto, como en el caso de los accidentes y las adicciones. Los temas que comunican funcionarios y académicos relacionados con el ámbito de la salud se centran en enfermedades desde el punto de vista biomédico, sin mencionar los estilos de vida de la comunidad. La violencia se representa como un fenómeno cotidiano, alarmista, social y creciente.

Un hallazgo de esta investigación es que, aunque los acontecimientos de violencia cambiaron día tras día durante el estudio, la manera de representarlos no varió mucho en los cuatro diarios: los hechos de violencia no se reportaron como un problema multicausal, solo se buscó a los responsables de la violencia, se etiquetó a los actores sociales y se utilizaron imágenes y un vocabulario sensacionalista para atraer al lector. Este tipo de cobertura no es exclusiva de los periódicos, sino que también es común en medios audiovisuales con el objetivo de elevar el rating (35). Esta investigación también permitió identificar que las representaciones de la violencia en la prensa no solo se construyen a partir del hecho, sino mediante todos los elementos que acompañan a una noticia: la imagen, la distribución del texto, la jerarquía, la continuidad y los calificativos. A su vez, las notas son construidas no solo por los reporteros, sino por sus fuentes de información y los actores sociales, además de intereses conjuntos de la prensa, del gobierno y particulares. En este contexto, las representaciones sociales aparecen cuando las personas discuten temas de interés mutuo o cuando existen acontecimientos dignos de interés para quienes tienen el control de los medios de comunicación (36).

Aunque el período temporal del estudio solo abarcó una quincena, se pudo constatar, mediante el análisis cuantitativo, que los periódicos no tuvieron diferencias significativas en sus contenidos de violencia. Desde una perspectiva cualitativa, hubo algunas variantes que permitieron identificar esbozos de las líneas editoriales de cada periódico.

El Informador es el diario que publicó menos notas, imágenes, aspectos de salud y calificativos en sus contenidos sobre violencia, lo que coincide con la descripción de diario conservador y poco crítico, que expresan autores como Sánchez Ruiz (17) y Domínguez-Gutiérrez (37). El Occidental tuvo una tendencia oficialista, como afirma TrejoDelarbre (19), porque además de que la autoridad fue la principal fuente de información de las notas, también hubo una predisposición a calificar de manera positiva el trabajo de las corporaciones. Asimismo, fue el diario que utilizó con más frecuencia un vocabulario sensacionalista y fotos en las que se exhibían cadáveres.

El periódico que más incluyó los testimonios de la comunidad en los hechos fue Mural; pero dicho esfuerzo por balancear las fuentes informativas fue insuficiente, ya que la mayoría de las noticias fue redactada desde un ángulo gubernamental. Los diarios priorizan la información que dan los funcionarios públicos sobre la de otros grupos, como las víctimas y los testigos de los hechos (18). Por su parte, Milenio citó más fuentes académicas y describió con más frecuencia la violencia como un problema de salud; sin embargo, estadísticamente, esta tendencia no fue significativa, por lo que no puede decirse que este diario es más crítico que los demás, como considera Zepeda-Martínez (16). En general, queda evidenciado que el vínculo entre violencia y salud pública es casi inexistente en la prensa escrita de Guadalajara.

El análisis de la construcción de las noticias de violencia en la prensa es un primer paso para ayudar a que académicos y periodistas trabajen este fenómeno desde una óptica más integral. En la práctica, este trabajo también puede ser pionero para diseñar nuevas investigaciones que apoyen la capacitación de los trabajadores de los medios de comunicación en la cobertura de hechos de violencia. 


\section{REFERENCIAS BIBLIOGRÁFICAS}

1. Organización Mundial de la Salud. Informe mundial sobre la violencia y la salud: resumen. Washington DC: Oficina Regional para las Américas, Organización Mundial de la Salud; 2002.

2. Instituto Nacional de Estadística y Geografía. Mujeres y hombres en México 2012 [Internet]. México: INEGl; 2013 [citado 2 nov 2014]. Disponible en: http://goo.gl/4Rsygh.

3. Más de 121 mil muertos, el saldo de la narcoguerra de Calderón: Inegi. Proceso [Internet]. 30 jul 2013 [citado 10 nov 2014]. Disponible en: http://www.proceso.com.mx/?p=348816.

4. Araujo-González R, Díaz-Llanes G. Un enfoque teórico-metodológico para el estudio de la violencia. Revista Cubana de Salud Pública. 2000;26(2):85-90.

5. Araiza-Sossa G. Las representaciones sociales de la violencia en las relaciones de pareja en la prensa de Medellín del siglo XXI: El Colombiano 2001-2008 y La Chiva 2002-2008. Revista Venezolana de Estudios de la Mujer. 2012;14(32): 71-97.

6. Moscovici S. Introduction. In: Herzlich C. Health and illness: A social psychological analysis. London: Academic Press; 1973.

7. Wagner W, Farr R, Jovchelovitch S, LorenziCioldi F, Marková I, et al. Theory and method of social representations. Asian Journal of Social Psychology. 1999;2(1):95-125.

8. Molina-Jácome I. Caracterización de la violencia urbana en Barranquilla desde la construcción noticiosa en la prensa popular: Caso del periódico Al Día. Palabra Clave. 2011;14(1):157-180.

9. Gasher M, Hayes MV, Ross I, Hackett RA, Gutstein D, Dunn JR. Spreading the news: social determinants of health reportage in Canadian daily newspapers. Canadian Journal of Communication. 2007;32:557-574.

10. Mercado-Martínez F, Robles-Silva L, Moreno-Leal N, Franco-Almazán C. Inconsistent journalism: the coverage of chronic diseases in the Mexican press. Journal of Health Communication. $2001 ; 6(3): 235-247$

11. Menéndez EL, Di Pardo RB. La representación social negativa de los procesos de salud/ enfermedad/atención en la prensa escrita. Salud Colectiva. 2008;4(1):9-30.
12. Krippendorff K, Wolfson L. Metodología de análisis de contenido: teoría y práctica. Barcelona: Paidós; 1990.

13. Minayo MCS. La etapa de análisis en los estudios cualitativos. En: Mercado F, Gastaldo D, Calderón C. Investigación cualitativa en salud en Iberoamérica: Método, análisis y ética. Guadalajara: Universidad de Guadalajara; 2002. p. 241-245.

14. Piñuel-Raigada J. Epistemología, metodología y técnicas del análisis de contenido. Sociolinguistic Studies. 2002;3(1):1-42.

15. Del Palacio C. Panorama general de la prensa en Guadalajara. Comunicación y Sociedad. 1992; (14-15):159-176.

16. Zepeda-Martínez CR. Periodismo científicotecnológico y cultural: Análisis de contenido de la prensa local en Guadalajara. [Tesis de maestría]. Tlaquepaque, Jalisco: ITESO; 2007.

17. Sánchez-Ruiz E. Apuntes para una historia de la prensa en Guadalajara. Comunicación y Sociedad. 1986;(4-5):10-38.

18. Mercado-Martínez FJ, Ascencio-Mera CD. La donación y el transplante de órganos en la prensa escrita: Un estudio en el Occidente de México. Comunicación y Sociedad. 2014;(21):161-180.

19. Trejo-Delarbre R. Prensa y gobierno: las relaciones perversas: Los medios, espacios y actores de la política en México. Comunicación y Sociedad. 1995;(25-26):35-55.

20. Tajonar H. Sentido adiós a Milenio [Internet]. 22 dic 2011 [citado 5 octubre 2015]. Disponible en: http://goo.gl/PzSWoM.

21. Vidal F. Circulación de los principales grupos de periódicos [Internet]. 16 feb 2009 [citado 15 may 2013]. Disponible en: http://goo.gl/b6YG4X.

22. Fregoso-Peralta G. La prensa de Guadalajara: cuatro versiones de una tragedia. Comunicación y Sociedad. 1992;(16-17):155-194.

23. Lesiona a un rival y es aprehendido. Mural. 4 sep 2013; Sec. Seguridad: 5B.

24. Martínez J. Hombre educa a balazos. El Occidental. 10 sep 2013; Sec. Policía: 12a.

25. Martínez J. Chamacos andaban de ladrones. El Occidental. 4 sep 2013; Sec. Policía: 12a.

26. Sánchez A. Madre ataca casa de sucesora. El Occidental. 5 sep 2013; Sec. Policía: 12a. 
27. Neri A. Imprudentes choferes provocan choque. El Occidental. 6 sep 2013. Sec. Policía: 12a.

28. Federico L, Gomes R, Piacenza P. Daily homicides: an analysis of the media discourse on homicides by firearms, Buenos Aires (Argentina) 2001-2002. Salud Colectiva. 2010;6(3):295-312.

29. Seale C. Health and media: an overview. Sociology of Health \& Illness. 2003;25(6):513-531.

30. Lara-Guevara Cl, Aguilar-López M, Mendoza-Torres CP. "Es la preocupación que nos tiene ahorita traumados": El impacto del cubrimiento sobre la violencia en la prensa escrita. Signo y Pensamiento. 2013;32(62):32-47.

31. González-Pérez G, Vega-López M, Cabrera-Pivaral C. Impacto de la violencia homicida en la esperanza de vida masculina de México. Revista Panamericana de Salud Pública. 2012;32(5):335-342.

32. Penalva C. El tratamiento de la violencia en los medios de comunicación. Alternativas: Cuadernos de Trabajo Social. 2002;(10):395-412.
33. Vázquez-González NIC. La violencia mediática: un estudio de caso. Convergencia. 2008; 15(47):103-125.

34. Herrera-Godina $M$, Méndez-Magaña $A$, Torres-López TM, Orozco-Valerio M. Los accidentes de tráfico desde el punto de vista de los medios impresos: Guadalajara, México 2011. Revista Española de Comunicación en Salud. 2013;4(1):27-42.

35. Ramonet I, Albiñana, A. La tiranía de la comunicación. Madrid: Editorial Debate; 2002.

36. Mora M. La teoría de las representaciones sociales de Serge Moscovici. Athenea DigitalRevista de Pensamiento e Investigación Social. 2002;(2):1-25.

37. Domínguez-Gutiérrez S. Periodismo científico: Caso de estudio de dos diarios del Estado de Jalisco, Mexico. En: Congreso Iberoamericano de Ciencia, Tecnología, Innovación y Educación. Buenos Aires: OEl; 2015. 